\title{
Risk analysis causing downtimes in production process of hot rolling mill
}

\author{
Marcela Malindzakova ${ }^{1}$, Dagmar Caganova ${ }^{2}$, Andrea Rosova ${ }^{1}$, Dusan \\ Malindzak $^{3}$
}

\begin{abstract}
This article is focused on the application of quality management tools in the production process of hot-rolled steel products, namely metal sheets and strips. The actual production of hot rolled products involves a set of main, support and management processes and network of interconnected relationships. The production process of hot rolled sheets and strips is characterized by strictly one-way direction of the production from the process beginning to end. It is a relatively simple, linear process based on precise continuity, time sequence and capacity settings. On the other hand, considering the technology involved, it is a system heavily dependent on stability of the important process parameters, such as temperature, etc.
\end{abstract}

Keywords: hot rolling, roughing mill, finishing mill, Pareto analysis, C-E diagnosis

\section{Introduction}

In this process it is not possible to repeatedly perform any operation. On top of that, for each sub-process there is only a limited time window available. For the production and non-production companies the quality is an integral tool used to maintain and improve competitiveness, either by maintaining the product quality or by providing outstanding quality of service. Suppliers should respect the requirements of customers and of the market. Their primary aim should be a continual effort not to lose customers and provide the highest quality products and services. Especially during the pre-production phases of a new product, that involves marketing, logistics planning and a drafting of the product, require increased efforts for the management. In the market environment for a successful operation of any new or a well established company it is important to rely on an analysis in combination with the support of quality management tools (security, evaluation, continuous improvement required parameters).

The main production flow of hot rolled sheets and strips consists of the following sub-processes:

1 Technical university of Košice, Faculty of Mining, Ecology, Process Control and Geotechnologies, Institute of Logistics, Park Komenskeho 14, Kosice

email: marcela.malindzakova@tuke.sk

2 STU Bratislava, Faculty of Materials Science and Technology in Trnava

3 Consultant, U. S. Steel Kosice, Vstupny areal U. S. Steel Kosice 
- Handling and heating of slabs.

- Hot strip rolling.

- Modification of coils (hot strip cutting into a sheet of metal tapes and discs) [1].

\subsection{Experimental tests}

The input material for this manufacturing process are the continuously cast slabs from the steelworks. To transport these slabs railway wagons are use to move them into the warehouse. The slab warehouse is logistically divided into two areas defined by the width of the slabs. The main machinery facilities of this operation are four pusher furnaces, where the slab heating takes place, with the slabs coming from the warehouse. The slabs are heated to the rolling temperature of about $1250^{\circ} \mathrm{C}$. The input temperature of slabs coming from the warehouse varies from $20^{\circ} \mathrm{C}$ to $400^{\circ} \mathrm{C}$, depending on the time they were imported by wagons. Reheated slabs from the pusher furnace move next by the conveyor and are arranged and prepared into a correct rolling sequence, for the hot rolling mill [2]. During the first part of this process the slab changes into a so called coble (intermediate rolling slab - defective work). The slabs then continues into the main rolling segment, where by continuous rolling it changes into a long roll-out hot strip.

After the main sequence, follows the segment of laminar strip cooling. The task here is to rapidly reduce the temperature down from $900^{\circ} \mathrm{C}$ to about $400^{\circ} \mathrm{C}-$ $600^{\circ} \mathrm{C}$, depending on customer requirements. By this controlled cooling the required mechanical properties are achieved as requested by the customer. The final step is to roll the hot strip in one of the three coilers in to create so called coils. An integral part of the production process is the regular control checks of selected process parameters [3]. Divided by the position within the production process, where the controls are carried out, these checks are divided into an input control, inter-operational control and checkout. Based on the character the controls can be divided into control checks performed by a man and control checks performed by a machine.

The input control - the pusher furnaces - the control cheeks the identity of the given slab, checks all the dimensions, namely the length, width and thickness of the slabs and looks for possible surface defects.

Inter-operational control - the pusher furnaces - temperature, duration time, excess air checks. Furthermore, checks are carried out on the rolling-pin, the next control checks the thickness, width, flatness, profile and strip temperature.

Checkout - after winding the coil right after the coilers, the HRM checks the thickness, width, and the surface quality of the strip. After cutting the strip into sheets or tapes by the slitting lines there is a check for width, thickness, surface quality of rolls of tapes. The employee that performs a visual inspection is annual- 
ly tested in regard to his abilities to perform visual inspection (kappa methodology) [4]. Right after the laminar cooling, there is a checkpoint performing control by a camera inspection system (CIS).

Due to basic physical principles, when at the beginning of the production process the heated slab from the pusher furnace during the rolling process gradually loses the temperature until it reaches the critical temperature for the hot strip winding into a coil. Any subsequent delivery of heat into the slab during the manufacturing process is possible. If the intermediate temperature drops below a critical value for given process, inevitably occurs a nonconforming product. Such a product is immediately removed from the production process and as scrap is returns back into production process as part of the initial charge. Any nonconforming product therefore worsens the yield rate fir hot rolling process.

In an effort to reduce the occurrences of nonconforming products during the main process of hot-rolled sheets and strips, a wide range of statistical analyses tools and quality management are used. From the most basic, such as the position analysis (median), and analysis of variance (dispersion) characteristics of the process, to more sophisticated tools, such as the control of a process based on the Shewhart control charts.

Management solves operational problems of production and logistics, as well as problems of a qualitative nature by brainstorming and subsequently developed Ishikawa diagram, to help determine the causes of this problem. Subsequently, using the Pareto principle they identified the cause the most serious problems, for which it is necessary to take a corrective action. A so called risk number is calculated. C-E diagnosis is the basis to create a so called FMEA (Failure Mode and Effect Analysis) [5].

FMEA process generally comprises the fallowing steps:

1. the determination of individual processes,

2. definition of possible errors, their causes and consequences (C-E diagnostics),

3. assessment of the current state (occurrence, detection, meaning of errors),

4. the calculation of risk number,

5. determination of activities requiring action - determination of critical sites (Pareto diagram of the most important issues),

6. proposals for corrective action [6].

The higher the risk number, the more urgent are the corrective actions. Also the selection of what design, manufacturing and testing measures are the most appropriate for forgiven situation is best determined by a qualified evaluation of factors - the occurrence frequency, importance, probability and possibility of exposing the defect:

- the probability of defects occurrence, which represents the probability that a particular cause will lead to the occurrence of the next defects,

- the importance of defects which can be reduced by changing the design or concept,

- the likelihood of detecting defects that can be increased by design improvements. 
The order and the necessity of improvement, is given by the value of the Risk number indicator - RNI / P - priority. As an illustrative example the following case study scenario wishes to present the solution to taperness - wedging (difference of the strip thickness at the right and left side) of hot-rolled sheets and strips. The CE diagram is divided into seven main groups, which are organized by Ishikawa principle of succession and continuity of the process in time: Materials, Methods, Technologies, Measurements, Men, Environment.

After processing of a comprehensive FMEA table within the corresponding software it is necessary to monitor the risk-number of individual causes. However the creation of just one Pareto diagram followed by a direct evaluation and selection of a corrective action carries a risk of incorrect logic [7].

Therefore, it is preferable to create as many Pareto diagrams as there are basic groups (7) and begin the corrective actions from the material - successively followed by technology A, B, C. This "step-by-step" procedure for the implementation of corrective measures reduces the risks involved in the follow-up groups. The question remains in regard to the repetition frequency of creating the FMEA table with options such as:

- after any corrective action,

- after a certain period of $3 / 6 / 12$.

FMEA results show that 27 identified processes may cause 50 different defects with risk numbers values ranging from 6 to 336. The sheer number of different defects indication in each category and the average risk in these categories shows that it is preferable to create a Pareto distribution for each category, rather than a single total for all 50 defects indications. The Pareto charts explain the "most problematic" and riskiest possible problems where the company must focus their efforts to maintain a defects-free production process.

\section{Results and discussion}

The Pareto analysis identified the causes of various categories that is the roughing mill, finishing mill and roll mill inspection [8 - 9].

For the roughing mill were specified the following processes:

1. Rolls cooling.

2. Pressure removal of scaling before the roughing mill stands.

3. Guiding the coble between stands of the roughing mill.

4. Vertical rollers - rolling of the coble in roughing mill (vertical rollers).

5. Horizontal rollers - rolling of coble in roughing mill.

The results are presented in Figure 1.

The results of the Pareto analysis show that the following processes influence the finishing mill: 
1. Keeping the strip between the stands of the finishing mill.

2. Pressure removal of scaling for the finishing mill.

3. Cooling of finishing mill rolls.

4. Front trimmer.

5. Establishment and transfer of coble.

6. Cooling of the strip between stands.

7. Greasing of rolls.

The results are presented in Figure 2.

The results of Pareto analysis show the importance of these processes for the roll mill inspection:

1. Transfer of the coil.

2. Winding the coil on a coiler.

3. Centering the strip before coilers.

4. The handling of the coil.

5. Inspection of the strip surface.

6. Coil check.

The results are presented in Figure 3.

For the problem of the excessive taperness - wedging of strips at the broad-line hot rolling mill based on the Pareto analysis results for the roughing mill category the excessive cooling of roller at the roughing mill causes the occurrence of slab exposed to drafts. This type of slabs occurs if the downtime lasts longer than $30 \mathrm{~min}$. dashboard based on web technologies.

Pareto analysis result for the finishing mill category identifies as the main cause for the excessive taperness - wedging of strips the formation of wedgeshaped coble. A wedge shaped coble occurs by an uneven left/right wedge correction during the rolling in roughing mill HRM. This type of coble must be marked as a non-conforming roll and must be removed into the warehouse of nonconforming production The problem in the process of coil transfer into the HOLD warehouse is omission of an physical inspection of the entire length of the strip. The result of a human error, which may be a wrong adjustment moves, sticking of roller surfaces, power and bearing failure affect also the second process, which is winding the coil on a coiler.

The main cause for the third process called centering the strip before coilers is a jammed setting mechanism of rulers, communication failure in the control system, or a lack of segments renovation. Difficulties in coil handling are caused by the malfunction of binding machine, a human error in the description of coils, defected weighing machine, improper weights calibration and failure of data transmission. Failure in the process of inspection of the strip surface is caused by insufficient lighting, unsuitable conditions for inspection (steam, water on the strip surface, temperature maps). 


\section{Conclusions}

For the analysis was used a process approach with a customer focus, which are the main requirements of international standards ISO 9001:2008 Quality management systems. Requirements. and ISO/TS 16949:2009 Quality management systems. Particular requirements for the application of ISO 9001:2008 for automotive production and relevant service part organizations. The article is focused on assessing the degree of risk of downtime. The FMEA method was used to assess such risk on a particular node in the manufacturing process of rolled steel on hot rolling mill. To highlight the most limiting factors hindering the production process optimisation and the logistics planning the Pareto analysis was used. The result of Pareto analysis presents the most urging problems for each assesses areas of influence.

This work was supported by the Slovak Research and Development Agency under the grants VEGA No. 1/0216/13.

\section{References}

[1] Laciak, M., Durdán, M., \& Kačur, J. (2012). Utilization of indirect measurement in the annealing process of the steel coils. Acta Metallurgica Slovaca, 18(1), 40-49.

[2] Baricová, D., Pribulová, A., \& Demeter, P. (Eds.). (2012). Utilizing of the metallurgical slag for production of cementless concrete mixtures. Metalurgija, 51(4), 465-468.

[3] Balog, M., Husár, J.: Methodical framework of flexibility production evaluation in terms of manufacturing plant, 2016. In: Key Engineering Materials : Operation and Diagnostics of Machines and Production Systems Operational States 3. Vol. 669 (2016), p. 568-577. ISBN 9783038356295.

[4] Balog, M., Knapčíková, L., Husár, J.: Plánovanie v strojárskej výrobe, 1. vyd. Brno : Tribun EU - 2016. - 86 p. ISBN 9788026310785.

[5] Futáš, P., \& Pribulová, A. (2014). Quality criteria as implement for advisement of metallurgical quality of grey iron. Evaluation of people and products features. Celje: University of Maribor. 99-118.

[6] Malindzakova, M. (2014). Process approach - a synergy of influences to address issues of quality and environmental management. Kosice: Technicka univerzita, F BERG, Habilitation thesis.

[7] Gašpar, M. (2015). Analysis tools of quality management in the logistics of the selected company. Kosice: Technicka univerzita, F BERG, Bachelor thesis.

[8] Company information U.S.Steel Košice, c. 1., 2011. b, [online]. Available on the Internet: <www.usske.sk/corpinfo/corpi-s.htm>.

[9] Saniuk, S., \& Saniuk, A. (2008). Rapid prototyping of constraint-based production flows in outsourcing, Advanced Materials Research, (44-46), 355-360.

[10] Husár, J., Dupláková, D.: Material flow planning for bearing production in digital factory, 2016. In: Key Engineering Materials : Operation and Diagnostics of Machines and Production Systems Operational States 3. Vol. 669 (2016), p. 541-550. ISBN 9783038356295 
Figure 1. Pareto analysis for roughing mill

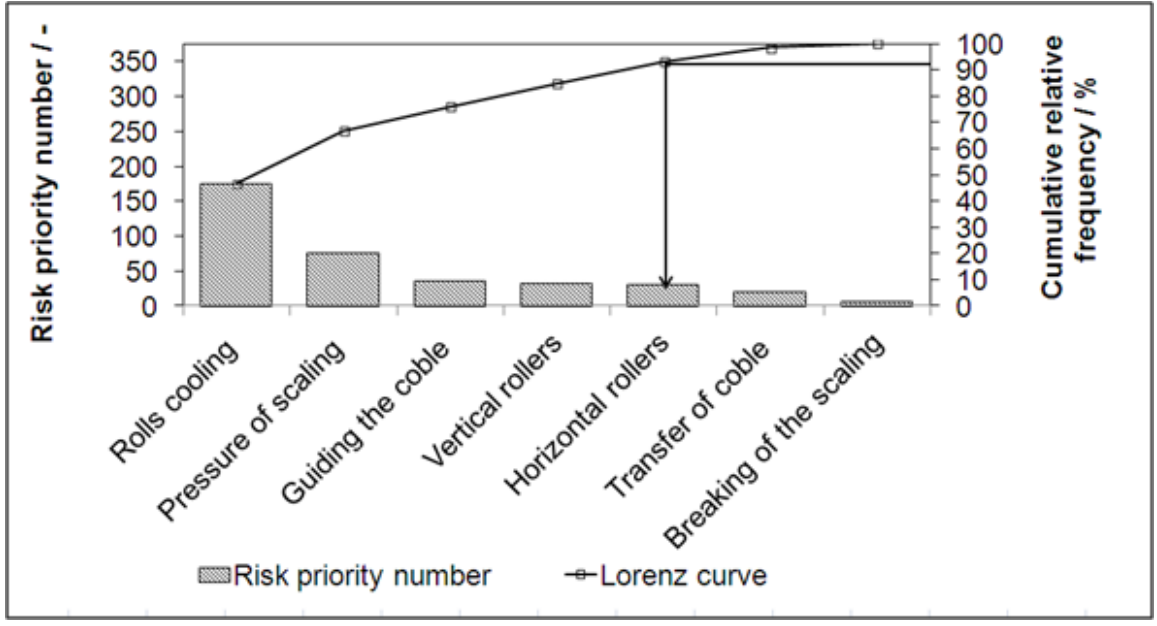

Figure 2. Pareto analysis for the finishing mill

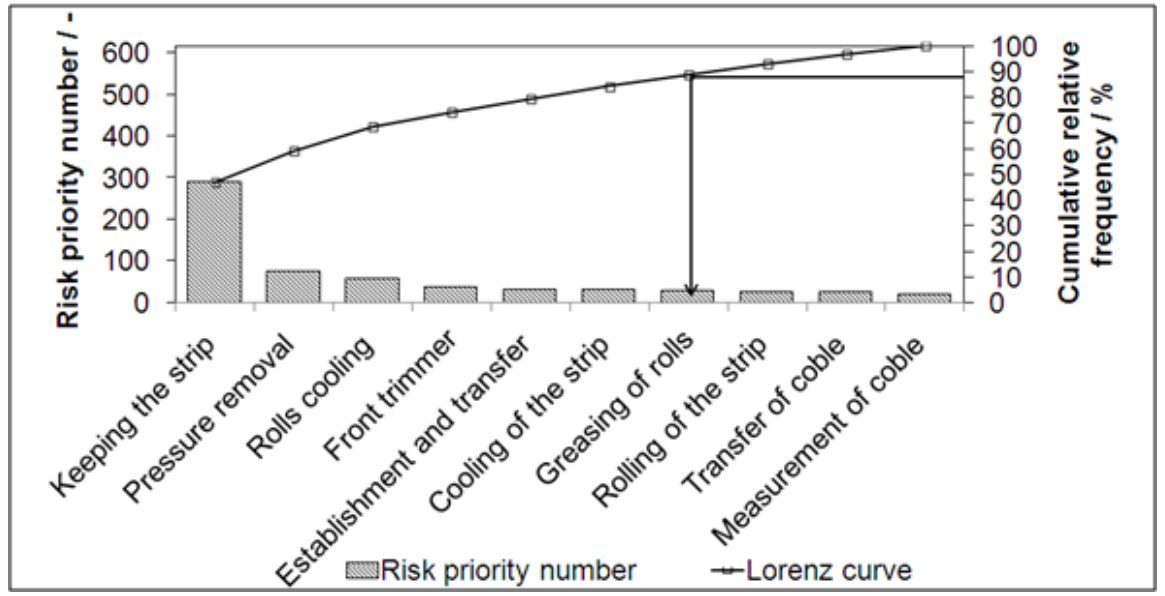


Figure 3. Pareto analysis for the roll mill inspection

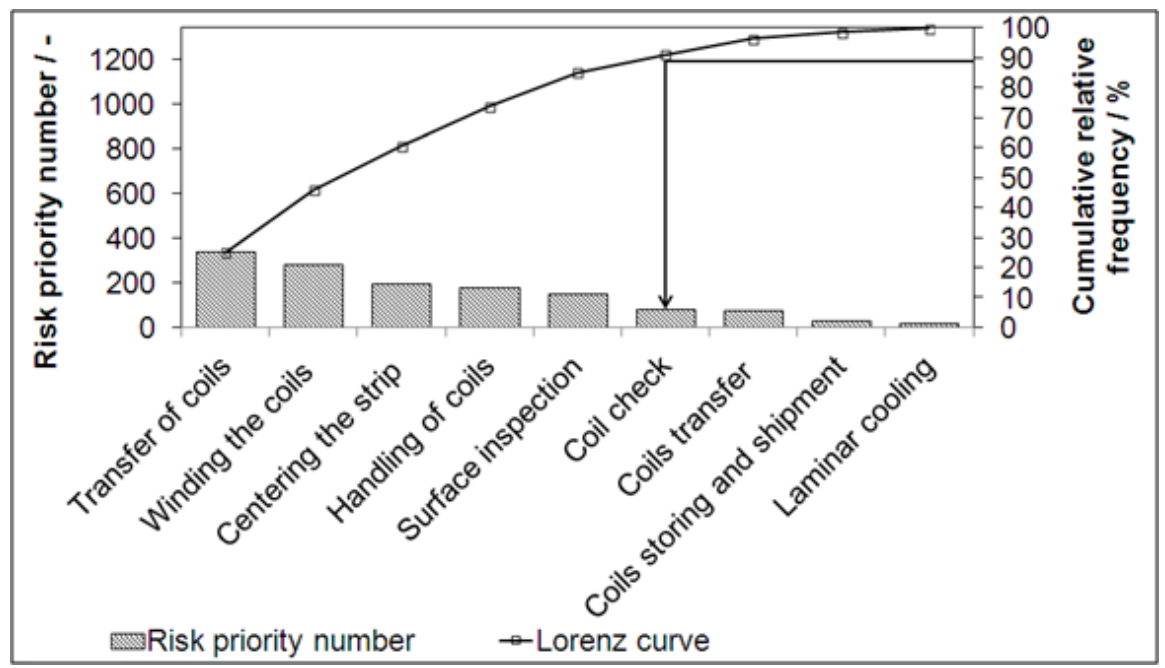

